\title{
Determinants of household food access among small farmers in the Andes: examining the path
}

\author{
Jessica Leah ${ }^{1}$, Willy Pradel ${ }^{2}$, Donald C Cole ${ }^{1, *}$, Gordon Prain ${ }^{2}$, \\ Hilary Creed-Kanashiro ${ }^{3}$ and Miluska V Carrasco ${ }^{3}$ \\ 'Dalla Lana School of Public Health, University of Toronto, 155 College Street, Toronto, Ontario, Canada, \\ M5T 3M7: ${ }^{2}$ International Potato Center, Lima, Peru: ${ }^{3}$ Insituto de Investigación Nutricional, Lima, Peru
}

Submitted 5 January 2011: Accepted 6 January 2012: First published online 21 February 2012

\begin{abstract}
Objective: Household food access remains a concern among primarily agricultural households in lower- and middle-income countries. We examined the associations among domains representing livelihood assets (human capital, social capital, natural capital, physical capital and financial capital) and household food access.

Design: Cross-sectional survey (two questionnaires) on livelihood assets.

Setting: Metropolitan Pillaro, Ecuador; Cochabamba, Bolivia; and Huancayo, Peru.

Subjects: Households ( $n$ 570) involved in small-scale agricultural production in 2008.

Results: Food access, defined as the number of months of adequate food provisioning in the previous year, was relatively good; $41 \%$ of the respondents indicated to have had no difficulty in obtaining food for their household in the past year. Using bivariate analysis, key livelihood assets indicators associated with better household food access were identified as: age of household survey respondent $(P=0 \cdot 05)$, participation in agricultural associations $(P=0 \cdot 09)$, church membership $(P=0 \cdot 08)$, area of irrigated land $(P=0 \cdot 08)$, housing material $(P=0 \cdot 06)$, space within the household residence $(P=0 \cdot 02)$ and satisfaction with health status $(P=0 \cdot 02)$. In path models both direct and indirect effects were observed, underscoring the complexity of the relationships between livelihood assets and household food access. Paths significantly associated with better household food access included: better housing conditions $(P=0 \cdot 01)$, more space within the household residence $(P=0 \cdot 001)$ and greater satisfaction with health status $(P=0 \cdot 001)$.

Conclusions: Multiple factors were associated with household food access in these peri-urban agricultural households. Food security intervention programmes focusing on food access need to deal with both agricultural factors and determinants of health to bolster household food security in challenging lower- and middle-income country contexts.
\end{abstract}

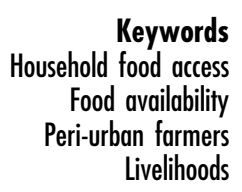

Globally the proportion of undernourished people has been increasing steadily since the mid-1990s in all regions except Latin America and the Caribbean, where undernourishment was declining ${ }^{(1)}$. However, recent food and economic crises have reversed this positive trend for Latin America and the Caribbean with undernourishment projected to increase by $8 \%$ in this region in $2010^{(1)}$. As food insecurity is a widely recognized contributor to undernourishment among a substantial number of households, contributors to household food insecurity need to be understood and programmes strengthened in these countries.

The WHO defines food security as a state in which 'all people at all times have both physical, social and economic access to sufficient, safe, nutritious food that meets their dietary needs and food preferences for an active and healthy life ${ }^{,(2)}$. The US Agency for International Development (USAID) Food and Nutrition Technical Assistance
Project further dissects food security into three components: availability, access and utilization. USAID defines household food access as the ability to acquire sufficient quality and quantity of food to meet all household members' nutritional requirements for productive lives,(3). Based upon preliminary qualitative work on comprehension of food security indicators and the observed extent of variation among our populations in a pilot study, the decision was made to focus on food access.

Peri-urban households, such as those studied here, face unique challenges and opportunities for accessing food. They often have diversified livelihoods, including multiple income streams from agricultural and non-agricultural sources which can strengthen their means of achieving household food security ${ }^{(4)}$. On the other hand, these households are often caught in the 'nutrition transition' between rural and urban consumption patterns, leading 
Table 1 Sustainable livelihoods framework: domains and key variables

\begin{tabular}{lll}
\hline Livelihood asset & \multicolumn{1}{c}{ Domain } & \multicolumn{1}{c}{ Variables } \\
\hline Human capital & Demographics; education; health status & $\begin{array}{l}\text { Demographics: age, sex } \\
\text { Education: level of education completed } \\
\text { Sealth status: self-reported satisfaction with health status } \\
\text { Community support and involvement: existence of community support, } \\
\text { satisfaction with community support, participation in community } \\
\text { organizations }\end{array}$ \\
& Community support and involvement & $\begin{array}{l}\text { Agricultural knowledge and practices: type of agricultural producer, } \\
\text { knowledge of integrated pest management, knowledge of organic } \\
\text { products }\end{array}$ \\
$\begin{array}{l}\text { Natural capital } \\
\begin{array}{l}\text { Physical capital } \\
\text { Financial capital }\end{array}\end{array}$ & $\begin{array}{l}\text { Farmland size } \\
\text { Housing conditions } \\
\text { Not available }\end{array}$ & $\begin{array}{l}\text { Housing conditions: degree of space, housing material } \\
\text { Not available }\end{array}$ \\
\hline
\end{tabular}

to both under- and overnutrition ${ }^{(5)}$. Urban or rural population development theory and practice often does not address these unique challenges of peri-urban populations. Additionally the literature tends to focus on urban nonagricultural producing households ${ }^{(6)}$ or rural agricultural producing households ${ }^{(7)}$, with little attention to the specific factors that influence household food access in peri-urban populations.

A theoretical model, based on a Sustainable Livelihoods (SL) framework ${ }^{(8)}$, was used to conceptualize the multitude of factors influencing household food access in peri-urban populations. The SL framework has been widely adopted by agencies and non-governmental organizations examining food access in populations, as it allows a holistic conception of the capabilities, assets and activities that are required for a livelihood, including improved household food $\operatorname{access}^{(9)}$. The SL framework places emphasis on people-centred analysis and examines people's objectives, their assets and their livelihood strategies. The framework considers five types of assets that are essential to achieving positive livelihood outcomes: human capital, social capital, natural capital, physical capital and financial capital. In order to achieve their objectives, people deploy their assets through engagement with different kinds of institutions and processes, such as markets, policy spheres or cultural contexts ${ }^{(8)}$.

The present study made use of available variables to act as domain indicators and estimate the contribution of the five livelihood assets to food access (see Table 1). No variables were available for financial capital. Our simplified SL framework could not incorporate analysis of the structures and processes through which assets are deployed. However, the framework helped to conceptualize which domains affected household food access, their relative importance and the ways in which they interacted ${ }^{(8)}$. We hypothesized that relationships among domains and food access could be mapped out with antecedent variables operating through other domains to influence the outcome of household food access (see Fig. 1). The purpose of the present paper was to model the associations among domains representing livelihood assets and household food access using path analyses to understand direct and indirect relationships.

\section{Methods}

\section{Study population}

The study population consisted of small-scale, agricultural producer households from three Central Andean metropolitan, peri-urban regions (Cochabamba, Bolivia; Pillaro, Ecuador; Huancayo, Peru) participating in the HortiSana Healthy and Sustainable Horticulture Production Project. Based on stakeholder consultations and community visits, we first selected districts with active horticultural production in each region. Within these districts, our research project objectives led us to recruit households with a range of approaches to production (i.e. organic producers, conventional producers or producers in transformation to organic production) and a range of produce disposition (i.e. primarily home consumption to primarily market oriented).

Although local authorities have lists of producing households, production and disposition approaches are not recorded in any agricultural census or survey data. Hence we relied on local authorities' informal knowledge, agricultural producer associations' lists, and information from agricultural extensionists with non-governmental organizations working in each area to contact different kinds of producing households. The producing households in turn referred us to similar farming households whom they knew, as per snowball sampling methods. This was particularly important for finding an adequate sample of organic production households, given the dominance of conventional farming methods.

\section{Questionnaires}

The HortiSana team administered two questionnaires in 2008: one producer questionnaire and one household questionnaire for each household. Within each household the individual most responsible for agricultural production was asked to respond to the production questionnaire. The household questionnaire was used with the individual most responsible for the managing the household. If it was not possible to survey the person in charge of the production or household, or if the same person was in charge 


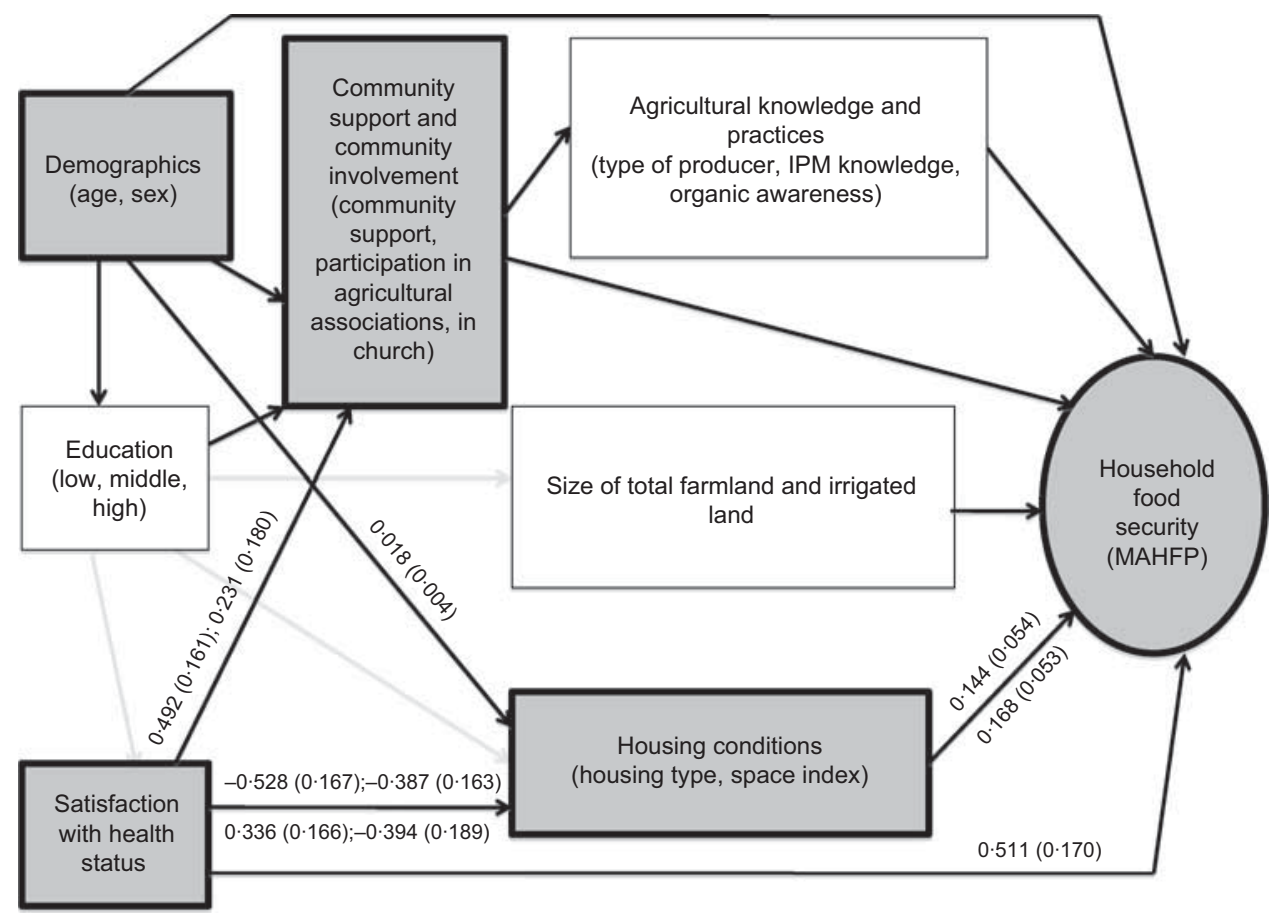

Fig. 1 Theoretical model of domains influencing household food access, based on a Sustainable Livelihoods framework. Shaded boxes denote domains and their variables which were included in the final model. Significant $(P<0.05)$ path estimates are shown, with standard errors in parentheses. For paths through 'Housing conditions' domain, estimates above the line are to and from housing type; estimates below the line are from space index. Paths with multiple estimates indicate categories of satisfaction with health status (two of somewhat, very much, completely). Paths from 'Education' are shaded lighter for clarity of path estimates. (IPM, integrated pest management; MAHFP, months with adequate household food provision)

of both, then the same person would respond to each questionnaire. All respondents were interviewed in person in their homes or their fields. In each region, approval was obtained from the corresponding ethics review board (Tribunal de Ética Médica Colegio Medico de Cochabamba, Bolivia; Comisión Nacional de Bioética del Consejo Nacional de Salud, Ecuador; Comité de Ética de Investigación Instituto de Investigación Nutricional, Peru). Participants completed written consent forms in each region.

The questionnaires were developed by a multidisciplinary research team and reflect diverse disciplinary perspectives. The production questionnaire included items on: respondents' age, sex and education; agricultural activity; crop type, quantity and destination; use of organic materials and fertilizers; irrigation for crops; production problems; pest control methods; pesticide use and exposure; animal husbandry; postharvest and marketing; type of land tenancy and area; financing of agricultural activities; and agricultural production training. The household questionnaire included items on: respondents' age and sex; housing conditions and personal assets; water supply; sanitation; self-report of health; food consumption, production and purchase; months of adequate household food provisioning; awareness of organic products; household income and expenses; money lending and family loans; crisis management; institutional and organizational networks and community support; and municipal government involvement and support (see Supplementary material). Pilot studies were performed to adapt the questionnaires to local idioms and to gain a better understanding of cultural interpretations in each region.

\section{Measures}

\section{Dependent variable}

Among several available measures of access to food, a common one is months of adequate household food provisioning (MAHFP) ${ }^{(3)}$. The MAHFP is particularly useful in agricultural populations as it captures changes in the household's ability to meet its food needs over the course of a year. It takes into consideration both social determinants and factors specific to an agricultural context (crop production, seasonality, storage problems, climatic changes and natural disasters, market fluctuations in prices, costs of agricultural inputs). The MAHFP was calculated by summing the number of months within a 12-month period that each household was unable to meet its food needs and subtracting the sum from 12; thus a higher score represents a household that has more consistent food access. Scores were categorized into three groups (most food access, middle, least food access) based on the frequency distribution of responses and the inference that extreme values - '12' (most food access, access to food all year round) and ' $\leq$ ' (least food access, implying at least a quarter of the year with food access problems) - were meaningful $^{(3)}$. 


\section{Independent variables}

Our (SL) framework ${ }^{(8)}$ and the preliminary descriptive analyses were used to organize variables from the two questionnaires into thematic domains. The domains represent the five types of assets (although they represent only a subsection of the very wide set of elements the assets represent). Variables were chosen as indicators for each domain to measure each type of asset (as noted in Fig. 1 and Table 1). The education categories were designated as 'lower education level' if the respondent had completed primary school or less, 'middle education level' if the respondent had incomplete or complete secondary school and 'higher education level' if the respondent had more than a secondary school education (including university, technical school or college). Satisfaction with health status was represented by the household respondent's selfreported satisfaction with current health status. Community support was determined by respondents' response to 'In your community do people help each other?' The quality of community support was determined by respondents' level of satisfaction with support received and the level of confidence they had in the organizations present in their community. Community involvement variables were examined by type of organization: agriculture associations, social programmes and churches. Agricultural association included involvement in any of the following agricultural programmes: irrigation committee, producer association, organic producer association, agricultural centre and the livestock association. Involvement in social programmes included involvement in any of the following: mother's/women's group, popular canteen, milk programme and parents' association for school activities. Church involvement was determined by respondents' response to 'Do you belong to a church?' Agricultural knowledge and practices domain was based on the following variables: type of agricultural producer (i.e. conventional, organic or both), knowledge of integrated pest management and knowledge of organic products. Housing conditions were based on two variables: (i) degree of space within the house, which was derived from the number of rooms divided by the number of occupants within a household; and (ii) the type of housing material. See Table 2 and Supplementary material for further information on variable construction. At the time of analysis, data on the following variables were not available for inclusion: use of organic materials and fertilizers, animal husbandry, crisis management, and personal assets, household income and expenses (the last three were not felt to be valid given concerns among respondents about new reporting requirements for tax assessments in two metropolitan regions).

\section{Statistical analysis}

Descriptive, within-domain comparison analyses and across-domain analyses were conducted with the STATA statistical software package version 11 (2009; StataCorp LP, College Station, TX, USA). Bivariate analyses were performed to identify associations between domains and food access (MAHFP score). These associations were conceptualized based on the theoretical model used (Fig. 1). Given that direction of the associations was not of immediate relevance at this stage, the $\chi^{2}$ test was utilized to examine associations of categorical independent variables by MAHFP score category. One-way ANOVA was used to examine the association of the continuous independent variables with MAHFP score category. Independent variables that were associated with MAHFP score $(P<0 \cdot 2)$ were selected for subsequent analysis.

With the reduced set of variables, path analyses were conducted to examine direct and indirect effects of age, sex, education, satisfaction with health status, community support and involvement, organic awareness, total irrigated land area and housing conditions on household food access guided by our SL framework (Fig. 1). Mplus Version 6 Base Program (Muthen \& Muthen, Los Angeles, CA, USA) was used because of its ability to accommodate continuous and categorical mediating and outcome variables ${ }^{(10)}$. Path models were reduced by sequentially removing variables below the set significance level of $P=0 \cdot 02$, while maintaining model goodness of fit. Goodness of fit was assessed using the overall $\chi^{2}$ test, the Comparative Fit Index (CFI) and the Tucker Lewis Index (TLI; $>0 \cdot 8$ is good for both the CFI and TLI), and the root mean square error of approximation (RMSEA, where $<0 \cdot 05$ is good) ${ }^{(10)}$.

\section{Results}

\section{Sample characteristics}

Of the 574 households selected there were 214 households in Peru, 215 households in Ecuador and 145 households in Bolivia. However, four respondents did not complete the food access questions from the household questionnaire, so the available sample comprised 570 households. Demographic characteristics of the household and producer respondents are shown in Table 3.

\section{Univariate analysis}

Age distribution patterns were similar across the household and producer questionnaire respondents. Respondents were predominantly young, over $60 \%$ of respondents were under 35 years of age (see Table 3). Sex of the respondents varied between the household and producer questionnaire respondents, with $68 \%$ of respondents from the household questionnaire being female compared with $57 \%$ of producers $(P=0 \cdot 00)$. Overall, one-third of participants had not completed primary school (32\%). However, education levels varied significantly between regions (more than 50\% of the study population in Peru finished a higher education level compared with $9 \%$ and $5 \%$ in Ecuador and Bolivia, respectively).

Exclusive use of organic agricultural practices was declared by $15 \%$ of producer respondents. However, less than $10 \%$ of all producers were knowledgeable about 
Table 2 Bivariate associations between domain indicators and food access (as measured by MAHFP): all respondents in Bolivia, Ecuador and Peru, HortiSana Healthy and Sustainable Horticulture Production Project, 2008 ( $n$ 570)

\begin{tabular}{|c|c|c|c|c|}
\hline \multirow[b]{2}{*}{ Indicator } & \multicolumn{3}{|c|}{ MAHFP score category } & \multirow{2}{*}{$\begin{array}{l}P \text { value (based on } \\
\text { ANOVA or } \chi^{2} \text { ) }\end{array}$} \\
\hline & $' \leq 9 ’(n$ 106) & '10 or 11 ' (n 232) & ‘12’ (n 232) & \\
\hline \multicolumn{5}{|l|}{ Household questionnaire respondents } \\
\hline \multicolumn{5}{|l|}{ Age (years) $\dagger$} \\
\hline Mean & $28 \cdot 0$ & $27 \cdot 4$ & $30 \cdot 3$ & $0 \cdot 05^{\star}$ \\
\hline SE & $1 \cdot 37$ & $0 \cdot 86$ & 0.99 & \\
\hline \multicolumn{5}{|l|}{ Producer questionnaire respondents } \\
\hline & $29 \cdot 8$ & $29 \cdot 4$ & $30 \cdot 6$ & 0.47 \\
\hline SE & $1 \cdot 46$ & 0.87 & $1 \cdot 02$ & \\
\hline \multicolumn{5}{|l|}{ Gender of household respondents } \\
\hline Women (\%, n 385) & $20 \cdot 5$ & $41 \cdot 3$ & $38 \cdot 2$ & $0 \cdot 12$ \\
\hline Men $(\%, n 185)$ & $14 \cdot 6$ & $39 \cdot 5$ & $46 \cdot 0$ & \\
\hline \multicolumn{5}{|l|}{ Gender of producer respondents } \\
\hline Women (\%, n 238) & $19 \cdot 3$ & $40 \cdot 3$ & $40 \cdot 3$ & 0.90 \\
\hline Men $(\%, n$ 325) & $17 \cdot 9$ & $41 \cdot 2$ & $40 \cdot 9$ & \\
\hline Missing $(\%, n 7)$ & $28 \cdot 6$ & $28 \cdot 6$ & $42 \cdot 9$ & \\
\hline \multicolumn{5}{|l|}{ Producer's education level } \\
\hline Low $(\%, n$ 302) & $21 \cdot 2$ & $39 \cdot 4$ & $39 \cdot 4$ & $0 \cdot 12$ \\
\hline Middle (\%, $n$ 162) & $13 \cdot 6$ & $49 \cdot 4$ & $37 \cdot 0$ & \\
\hline High $(\%, n 67)$ & $16 \cdot 4$ & $37 \cdot 3$ & $46 \cdot 3$ & \\
\hline Missing $(\%, n 39)$ & $23 \cdot 1$ & $20 \cdot 5$ & $56 \cdot 4$ & \\
\hline \multicolumn{5}{|l|}{ Community support } \\
\hline Never $(\%, n 128)$ & $26 \cdot 7$ & $36 \cdot 7$ & $36 \cdot 7$ & $0 \cdot 13$ \\
\hline Sometimes $(\%, n 321)$ & $16 \cdot 8$ & $41 \cdot 4$ & $41 \cdot 7$ & \\
\hline Always $(\%, n 121)$ & $14 \cdot 9$ & $43 \cdot 0$ & $42 \cdot 2$ & \\
\hline \multicolumn{5}{|l|}{ Satisfaction with community support received } \\
\hline Not satisfied $(\%, n 39)$ & $25 \cdot 6$ & $43 \cdot 6$ & $30 \cdot 8$ & 0.50 \\
\hline Satisfied $(\%, n$ 343) & $16 \cdot 9$ & $41 \cdot 7$ & $41 \cdot 4$ & \\
\hline Very satisfied $(\%, n$ 186) & $20 \cdot 4$ & $38 \cdot 2$ & $41 \cdot 4$ & \\
\hline Missing $(\%, n 2)$ & 0.0 & $50 \cdot 0$ & $50 \cdot 0$ & \\
\hline \multicolumn{5}{|l|}{ Participation in agricultural associations (No as reference) } \\
\hline Yes $(\%, n 433)$ & $16 \cdot 6$ & $42 \cdot 3$ & $41 \cdot 1$ & $0.09^{*}$ \\
\hline \multicolumn{5}{|l|}{ Church membership (No as reference) } \\
\hline Yes $(\%, n$ 404) & $16 \cdot 6$ & $43 \cdot 1$ & $40 \cdot 4$ & $0.08^{*}$ \\
\hline Participation in social programmes (No as reference) & & & & \\
\hline Yes $(\%, n 171)$ & $15 \cdot 8$ & $45 \cdot 0$ & $39 \cdot 2$ & 0.32 \\
\hline Type of agricultural producer & & & & \\
\hline Both $(\%, n 361)$ & $18 \cdot 8$ & $40 \cdot 7$ & $40 \cdot 4$ & 0.99 \\
\hline Conventional $(\%, n 116)$ & $17 \cdot 2$ & $41 \cdot 4$ & $41 \cdot 4$ & \\
\hline Organic/ecological $(\%, n 86)$ & $18 \cdot 6$ & $40 \cdot 7$ & $40 \cdot 7$ & \\
\hline Missing $(\%, n 7)$ & $28 \cdot 6$ & $28 \cdot 6$ & $42 \cdot 9$ & \\
\hline Knowledge of integrated pest management (No as reference) & & & & \\
\hline Yes $(\%, n 53)$ & $24 \cdot 5$ & $32 \cdot 1$ & $43 \cdot 4$ & $0 \cdot 31$ \\
\hline Missing $(\%, n 7)$ & $28 \cdot 6$ & $28 \cdot 6$ & $42 \cdot 9$ & \\
\hline Knowledge of organic products (No as reference) & & & & \\
\hline Yes $(\%, n 324)$ & $20 \cdot 7$ & $37 \cdot 7$ & $41 \cdot 7$ & $0 \cdot 12$ \\
\hline Missing (\%, $n 5)$ & $40 \cdot 0$ & $20 \cdot 0$ & $40 \cdot 0$ & \\
\hline Area of irrigated farmland $\ddagger$ & & & & \\
\hline $0-149 \mathrm{~m}^{2}(\%, n 45)$ & $28 \cdot 9$ & $31 \cdot 1$ & $40 \cdot 0$ & $0.08^{*}$ \\
\hline $150-224 \mathrm{~m}^{2}(\%, n 161)$ & $16 \cdot 8$ & $39 \cdot 8$ & $43 \cdot 5$ & \\
\hline $225-299 \mathrm{~m}^{2}(\%, n 216)$ & $14 \cdot 4$ & $46 \cdot 8$ & $38 \cdot 9$ & \\
\hline$\geqslant 300 \mathrm{~m}^{2}(\%, n 148)$ & $23 \cdot 7$ & $35 \cdot 8$ & $40 \cdot 5$ & \\
\hline Type of housing material & & & & \\
\hline Earthen walls (\%, $n$ 258) & $20 \cdot 7$ & $46 \cdot 5$ & $32 \cdot 8$ & $0.06^{*}$ \\
\hline Other (reed mats \& stone with lime or cement \& wood) $(\%, n 30)$ & $16 \cdot 7$ & $33 \cdot 3$ & $50 \cdot 0$ & \\
\hline Cement unfinished $(\%, n$ 99) & $17 \cdot 2$ & $36 \cdot 4$ & $46 \cdot 5$ & \\
\hline Cement finished $(\%, n$ 185) & $16 \cdot 8$ & $36 \cdot 2$ & $47 \cdot 0$ & \\
\hline Space in household residence & & & & \\
\hline $0-0.4(\%, n 112)$ & $25 \cdot 0$ & $41 \cdot 1$ & 33.9 & $0.02^{\star \star}$ \\
\hline $0.5-0.9(\%, n 361)$ & $18 \cdot 8$ & $42 \cdot 7$ & $38 \cdot 5$ & \\
\hline $1 \cdot 0-1 \cdot 9(\%, n 71)$ & $9 \cdot 9$ & $32 \cdot 4$ & $57 \cdot 8$ & \\
\hline$\geqslant 2 \cdot 0(\%, n 26)$ & $11 \cdot 5$ & $34 \cdot 6$ & $53 \cdot 9$ & \\
\hline $\begin{array}{l}\text { Household respondent's satisfaction with health status (Not at all/A litt } \\
\text { reference) }\end{array}$ & & & & \\
\hline Somewhat $(\%, n$ 194) & $17 \cdot 1$ & $42 \cdot 2$ & $40 \cdot 6$ & $0 \cdot 02^{\star \star}$ \\
\hline Very much $(\%, n 209)$ & $20 \cdot 7$ & $39 \cdot 0$ & $40 \cdot 4$ & \\
\hline Completely (\%, $n$ 93) & $11 \cdot 1$ & $44 \cdot 4$ & $44 \cdot 4$ & \\
\hline
\end{tabular}

MAHFP, months of adequate household food provisioning.

Association was statistically significant: ${ }^{\star} P<0 \cdot 1$, ${ }^{\star \star} P<0 \cdot 05$.

tAge is continuous.

$\ddagger$ Area of irrigated farmland represents the area of the producer’s total plots of farmland that are irrigated in square metres, divided into categories.

$\S$ Space in household residence represents the number of rooms in the residence (without counting bathroom, kitchen, storeroom, halls or garage) divided by the number of people who occupy the residence, and then categorized. 
Table 3 Demographic characteristics of all respondents in Bolivia, Ecuador and Peru, HortiSana Healthy and Sustainable Horticulture Production Project, 2008

\begin{tabular}{|c|c|c|c|c|}
\hline \multirow[b]{2}{*}{ Variable } & \multicolumn{2}{|c|}{$\begin{array}{l}\text { Household questionnaire respondents } \\
\qquad(n 570)\end{array}$} & \multicolumn{2}{|c|}{$\begin{array}{l}\text { Producer questionnaire respondents } \\
\qquad(n 570)\end{array}$} \\
\hline & $n$ & $\%$ & $n$ & $\%$ \\
\hline \multicolumn{5}{|l|}{ Age (years) } \\
\hline $0-34$ & 368 & 65 & 354 & 62 \\
\hline $35-44$ & 109 & 19 & 112 & 20 \\
\hline $45-59$ & 85 & 15 & 85 & 15 \\
\hline$>59$ & 8 & 1 & 19 & 3 \\
\hline \multicolumn{5}{|l|}{ Sex } \\
\hline Female & 385 & 68 & 325 & 57 \\
\hline Male & 185 & 32 & 238 & 42 \\
\hline Missing & 0 & 0 & 7 & 1 \\
\hline Educationt & $\mathrm{N} / \mathrm{A} \ddagger$ & & & \\
\hline Lower education level & & & 302 & 53 \\
\hline Middle education level & & & 162 & 28 \\
\hline Higher education level & & & 67 & 12 \\
\hline Missing & & & 39 & 7 \\
\hline
\end{tabular}

tEducation categories: lower education level represents individuals with kindergarten, incomplete primary school, complete primary school education and those who are literate; middle education level represents individuals with incomplete and complete secondary education; higher education level represents individuals with incomplete university, complete university, incomplete trade school and complete trade school.

‡Not available: question was not asked of the household respondents.

integrated pest management methods. Food access as measured by MAHFP was relatively high; $41 \%$ of household respondents did not experience any difficulties in obtaining food for their household in the past 12 months (MAHFP score of 12). The proportion of households reporting difficulties in obtaining food for their households for 3 months or more in the past 12 months was $18 \cdot 6 \%$ (MAHFP score of $\leq 9$ ).

\section{Bivariate analysis}

Table 2 shows the association (significant at $P<0 \cdot 1$ ) between the domain variables and MAHFP scores. Variables associated with better food access included: household questionnaire respondents' older age $(P=0 \cdot 05)$, greater satisfaction with health status $(P=0 \cdot 02)$, participation in agricultural associations $(P=0 \cdot 09)$, church membership $(P=0 \cdot 08)$, larger area of irrigated farmland $(P=0 \cdot 08)$, type of housing material including cement $(P=0 \cdot 06)$ and more space within the household residence $(P=0 \cdot 02)$.

There was no significant association between the following variables and MAHFP category: age of the producer $(P=0.47)$ or the sex of both questionnaire respondents (household $P=0 \cdot 12$, producer $P=0 \cdot 90)$, education level $(P=0 \cdot 12)$, community support $(P=0 \cdot 13)$, satisfaction with community support received $(P=0 \cdot 50)$, participation in social programmes $(P=0 \cdot 32)$, type of agricultural producer $(P=0.99)$, knowledge of integrated pest management $(P=0 \cdot 31)$, awareness of organic products $(P=0 \cdot 12)$ and total area of farmland $(P=0 \cdot 72)$. However, education, gender of household respondent and awareness of organic products variables were retained based on the associations identified in our theoretical model and their borderline statistical significance. Variables excluded at this stage, based on lack of significant association and/or domain coverage by other variables, were: age of producer respondents, gender of producer respondents, satisfaction with community support received, participation in social programmes, type of agricultural producer, knowledge of integrated pest management and area of total farmland.

\section{Patb analyses}

Guided by our original theoretical model relating livelihoods and food security, the statistically significant bivariate associations and paths $(P<0 \cdot 2)$ and the overall goodness of fit, a final model was developed (see Fig. 1 bolded boxes). Figure 1 sets out the significant path estimates $(P<0 \cdot 05)$ in our final model, initially for each intermediate variable and then final paths to household food security. Type of housing material, space in household residence and satisfaction with health status had more significant associations with food access $(P<0 \cdot 01)$ than other variables, including age of the household respondent and community support, at the final stage. Satisfaction with health status was significant in several of the earlier paths, mapping on to space in the household residence, type of housing material and community support. The complex nature of relationships among factors can be seen even more clearly through examination of the indirect effects in Table 4, where different levels of household respondents' satisfaction with health status can be seen to be associated with housing material and household food security in different ways.

\section{Discussion}

We sought to examine the associations among domains representing livelihood assets (human capital, social capital, 
Table 4 Direct and indirect effects along paths to household food access among all respondents in Bolivia, Ecuador and Peru, HortiSana Healthy and Sustainable Horticulture Production Project, 2008

\begin{tabular}{|c|c|c|c|}
\hline Variable & Path estimate & SE & $P$ value \\
\hline \multicolumn{4}{|c|}{ Effects of 'age of household questionnaire respondent' on 'household food access' } \\
\hline \multicolumn{4}{|c|}{ Direct effects } \\
\hline Household food access & 0.006 & 0.003 & 0.086 \\
\hline \multicolumn{4}{|c|}{ Indirect effects on household food access through } \\
\hline Type of housing material & $-0 \cdot 001$ & 0.001 & $0 \cdot 165$ \\
\hline Spacing in household residence & 0.003 & 0.001 & 0.007 \\
\hline \multicolumn{4}{|c|}{ Effects of 'satisfaction with health status (somewhat)' on 'household food access' } \\
\hline \multicolumn{4}{|l|}{ Direct effects } \\
\hline Household food access & $0 \cdot 156$ & $0 \cdot 154$ & $0 \cdot 309$ \\
\hline \multicolumn{4}{|c|}{ Indirect effects on household food access through } \\
\hline Community support & $0 \cdot 046$ & 0.029 & $0 \cdot 113$ \\
\hline Type of housing material & -0.076 & 0.037 & $0 \cdot 040$ \\
\hline Spacing in household residence & 0.042 & 0.031 & $0 \cdot 177$ \\
\hline \multicolumn{4}{|c|}{ Effects of 'satisfaction with health status (very much)' on 'household food access' } \\
\hline \multicolumn{4}{|c|}{ Direct effects } \\
\hline Household food access & $0 \cdot 210$ & $0 \cdot 147$ & $0 \cdot 154$ \\
\hline \multicolumn{4}{|c|}{ Indirect effects on household food access through } \\
\hline Community support & 0.048 & 0.030 & $0 \cdot 108$ \\
\hline Type of housing material & -0.056 & 0.031 & 0.076 \\
\hline Spacing in household residence & 0.056 & 0.033 & $0 \cdot 087$ \\
\hline \multicolumn{4}{|c|}{ Effects of 'satisfaction with health status (completely)' on 'household food access' } \\
\hline \multicolumn{4}{|l|}{ Direct effects } \\
\hline Household food access & 0.511 & $0 \cdot 170$ & 0.003 \\
\hline \multicolumn{4}{|c|}{ Indirect effects on household food access through } \\
\hline Community support & 0.023 & 0.021 & 0.289 \\
\hline Type of housing material & 0.010 & 0.028 & 0.723 \\
\hline Spacing in household residence & $0 \cdot 066$ & $0 \cdot 038$ & $0 \cdot 081$ \\
\hline
\end{tabular}

natural capital, physical capital) and food access as represented by months of adequate food provisioning in the previous year in a population of Andean peri-urban farm households. The final model explaining the effect of livelihood assets on food access included variables representing the domains of human capital (age of household respondent), social capital (community support, participation in agricultural associations) and physical capital (housing conditions and space in household residence).

We found complete satisfaction with health status, space in the household residence and housing material containing cement to be strongly associated with food access. While little research exists examining the direct associations between food access and each of these significant variables, there are many studies that examine the indirect effects. The positive association of satisfaction with health status and food access is consistent with the results of several studies ${ }^{(11-17)}$; however, the cross-sectional nature of our design makes it difficult to comment on the direction of relationships. Food-secure households may rate their health more favourably because better health may act as an asset which enables households to have better food access through improved productivity and economic growth $^{(18)}$. Conversely, individuals may have better physical health because better food access decreases their susceptibility to infectious diseases ${ }^{(19)}$.

The association between space in the household residence and food access may be explained by the link between space in a household and physical health status: higher density of households is associated with higher incidence of infectious diseases and poorer physical health $^{(20,21)}$. Crowding has also been shown to correlate with lower socio-economic status, which has in turn been shown to be strongly associated with both poor health and food access outcomes ${ }^{(22)}$. The positive association between better housing material, such as more durable and less permeable material (wood, stone, cement $v$. adobe or earthen walls), and better food access is consistent with results from other studies examining housing conditions and health outcomes ${ }^{(23-25)}$. Housing with structural problems (leaky roofs, damp floors, rot in the window frames) has been highly associated with poor individual health status ${ }^{(23-25)}$. Given the strong association between physical health and food access, it is plausible that our findings can be explained by the improvement in health which is associated with improved housing conditions ${ }^{(19)}$.

Corroborating the results of previous work, our findings illustrated a moderate association between food access and age of household questionnaire respondent and community support, such that older households had better food access. Individuals, over the course of their lives, may gain knowledge and integrate into social networks that enable them to engage in more successful agricultural production strategies ${ }^{(26)}$. Alternatively, younger families may have more dependants than older, more mature families, and mature families may be more likely to be more economically stable and food secure because they have more adults to generate income through employment or labour in agricultural production ${ }^{(27)}$. 
The lack of statistically significant associations between food access and gender of household respondents, education, knowledge of integrated pest management and type of agricultural producer deserves comment. While gender was ultimately dropped from our final model, previous research has often identified a strong association between gender and increased food access (with males often being more food secure ${ }^{(28)}$. However, since the food access measure used focused on household-level food access, no distinction could be made between the individuals' level of food access within the home.

The variables education and knowledge of integrated pest management were not significantly related to food access. This could have been caused by the respondents' awareness of healthier choices in their agricultural practices and improved techniques, which may not be effective in overcoming other barriers to food access. Such barriers could include extreme climatic conditions (drought, flooding) or insufficient access to financial capital to purchase capital goods (biological control products, clean seed), which may have more influence on agricultural production and hence household food access ${ }^{(29,30)}$. Similarly, type of agricultural producer may not be specific enough. Given previous research showing benefits in both productivity and reduced cost of agricultural inputs for organic agricultural production $^{(31-33)}$, our question may not have accurately captured the degree to which producers were actively practising organic agricultural practices as most respondents indicated being both traditional (chemical dependent) and organic producers (64\%). The relationship between agricultural practices and food access was more readily seen in producers' participation in agricultural associations, including organic producer associations. In future studies, additional information about a household's range of agricultural activities, including income-generating livestock-raising, may be beneficial for obtaining a more accurate picture of the household's productivity and resources. This is consistent with previous research such as an Urban Harvest Project, where vegetable production was not associated with household food security, but pig production was ${ }^{(34)}$.

Strengths of the current study were the use of a purposive sample that reflected a range of agricultural producers (from agro-industrial through to organic producers), a broad range of sustainable livelihood characteristics assessed for associations with food access and the use of a food access measure (MAHFP) that captures the fluctuation in food access with agricultural production patterns ${ }^{(3)}$.

However, one major limitation of the study is the exclusive use of the MAHFP as our food access measure. Despite its ability to capture fluctuations in food access, the MAHFP is only one measure of household food access and as such it does not capture the full range of barriers to improved household food access, including adequate food quality and food diversity ${ }^{(3)}$. Food diversity has been shown to be particularly important in agricultural populations, as development projects centred on agricultural interventions have often found that increasing food production does not necessarily improve nutrition or health of producing households ${ }^{(35,36)}$. To provide a more comprehensive measure of household food access, the USAID requires all new Multi-Year Assistance Programs to include two indicators: household dietary diversity (HDDS) and MAHFP ${ }^{(3)}$. Without the complementary HDDS measure it is difficult to discern the quality aspects of food access. However, given the limited availability of processed data (analysis time constraints) and the type of data collected (the interdisciplinary approach of the HortiSana project introduced trade-offs between data sets in order to ensure the richness of data in other domains of livelihoods), the present study offers a preliminary examination of food access issues in the novel context of a peri-urban agricultural population, a group for which little published data currently exist.

Another potential limitation of our study is the use of purposive or snowball sampling. The intent of this sampling strategy was to recruit a range of production and disposition approaches in an efficient manner in regions where conventional farming was dominant. We successfully obtained sufficient range and numbers in each category for meaningful comparisons However, we caution against generalization to the metropolitan regions under study or to peri-urban agricultural producing populations as a whole. Nevertheless, the study can serve to generate hypotheses and discussion that could be more fully explored in larger-scale, more food security-focused, probability-based sample surveys. Another challenge in our study was having sufficient information to analyse each type of capital or asset in the SL framework due to the constraints on data collection and processing mentioned above. However, with the information available and following the Department for International Development guidance sheets on the SL framework, the variables selected were the best available measures to represent the livelihood assets.

Future studies could include measures of household dietary diversity, agricultural productivity and measures of ecological conditions (such as measures of rainfall), each of which may be useful to further enhance our understanding of food access in peri-urban agricultural households. Larger sample sizes would be required to handle the dangers of small cell counts which occur when examining multiple variables simultaneously (i.e. in the path analyses) with the associated danger of unstable estimates. Future longitudinal research should aim to assess both the stability of the associations observed and more specifically the direction of the relationships that were identified here. Our findings do contribute to a greater global understanding of the complex relationships between livelihood assets and food access in peri-urban agricultural households. Interventions that aim to support small producers in lower- and middle-income countries 
must deal with a wide range of domains in order to achieve desired improvements in both agricultural sustainability and food access.

\section{Acknowledgements}

Main funding for the HortiSana project came from the Canadian International Development Agency and the International Development Research Center (grant \#104317-001). In addition, some staffing costs were funded by the University of Toronto Dalla Lana School of Public Health and by the International Potato Center (CIP). All contributing authors have no conflicts of interest. Authors' contributions to the manuscript were as follows: conception (G.P., D.C.C.); design (D.C.C., G.P., H.C.-K.); data collection (W.P., M.V.C.); data analysis (W.P., J.L.); writing (J.L.); interpretation (all); and revision (J.L., G.P., D.C.C., W.P., H.C.-K.).

\section{Supplementary material}

For supplementary material for this article, please visit http://dx.doi.org/10.1017/S1368980012000183

\section{References}

1. Food and Agriculture Organization of the United Nations (2009) The State of Food Insecurity in the World Economic Crisis: Impacts and Lessons Learned. Rome: FAO; available at http://www.fao.org/docrep/012/i0876e/ i0876e00.htm

2. Food and Agriculture Organization of the United Nations (2001) Trade reforms and food security. In Food Security: Concepts and Measurement, chapter 2. Rome: FAO; available at http://www.fao.org/docrep/005/y4671e/y4671e06.htm

3. Bilinsky P \& Swindale A (2007) Months of Adequate Household Food Provisioning (MAHFP) for Measurement of Household Food Access: Indicator Guide. Washington, DC: Food and Nutrition Technical Assistance Project, Academy for Educational Development; available at http:// www.fantaproject.org/publications/hdds_mahfp.shtml

4. Tacoli C (1998) Bridging the Divide: Rural-Urban Interactions and Livelihood Strategies. Gatekeeper Series no. 77. London: International Institute for Environment and Development - Sustainable Agriculture and Rural Livelihoods Programme; available at http://www.iied.org/pubs/ display.php?o=6144IIED

5. Popkin BM (1999) Urbanization, lifestyle changes and the nutrition transition. World Dev 27, 1905-1916.

6. Lorenzana P \& Mercado C (2002) Measuring household food security in poor Venezuelan households. Public Health Nutr 5, 851-858.

7. Knueppel D, Demment M \& Kaiser L (2009) Validation of the household food insecurity access scale in rural Tanzania. Public Health Nutr 13, 360-367.

8. Department for International Development (1999) Sustainable Livelihoods Guidance Sheets. London: Department for International Development; available at http://www. ennonline.net/resources/667

9. Thomson AM (2001) Food security and sustainable livelihoods: the policy challenge. Development 44, 24-28.

10. Muthen LK \& Muthen BO (2007) MPLUS: Statistical Analysis with Latent Variables. User's Guide. Los Angeles, CA: Muthen \& Muthen.
11. Walker JL, Holben DH, Kropf ML et al. (2007) Household food insecurity is inversely associated with social capital and health in females from the Special Supplemental Nutrition Program for Women, Infants, and Children Households in Appalachian Ohio. J Am Diet Assoc 107, 1989-1993.

12. Holben DH \& Pheley AM (2006) Diabetes risk and obesity in food-insecure households in rural Appalachian Ohio. Prev Chronic Dis 3, A82.

13. Pheley AM, Holben DH, Graham AS et al. (2002) Food security and perception of health status: a preliminary study in rural Appalachia. J Rural Health 18, 447-454.

14. Nelson K, Cunningham W, Andersen R et al. (2001) Is food insufficiency associated with health status and health care utilization among adults with diabetes? J Gen Intern Med 16, 404-411.

15. Siefert K, Heflin CM, Corcoran ME et al. (2001) Food insufficiency and the physical and mental health of lowincome women. Women Health 32, 159-177.

16. Stuff JE, Casey PH, Szeto KL et al. (2004) Household food insecurity is associated with adult health status. J Nutr $\mathbf{1 3 4}$, 2330-2335.

17. Vozoris NT \& Tarasuk VS (2003) Household food insufficiency is associated with poorer health. J Nutr 133, 120-126.

18. Bloom DE, Canning D \& Sevilla J (2004) The effect of health on economic growth: a production function approach. World Dev 32, 1-13.

19. Hassan R, Scholes R \& Ash N (2005) Ecosystems and Human Well-Being: Current State and Trends: Findings of the Conditions and Trends Working Group. Washington, DC: Island Press.

20. Early J, Davis SW, Quandt SA et al. (2006) Housing characteristics of farmworker families in North Carolina. J Immigr Minor Health 8, 173-184.

21. Yamamoto S, Louis VR, Sie A et al. (2010) Household risk factors for clinical malaria in a semi-urban area of Burkina Faso: a case-control study. Trans R Soc Trop Med Hyg 104, 61-65.

22. Melki IS, Beydoun HA, Khogali M et al. (2004) Household crowding index: a correlate of socioeconomic status and inter-pregnancy spacing in an urban setting. $J$ Epidemiol Community Health 58, 476-480.

23. Navarro C, Ayala L \& Labeaga JM (2010) Housing deprivation and health status: evidence from Spain. Empir Econ 38, 555-582.

24. Dunn JR (2000) Housing and health inequalities: review and prospects for research. Housing Stud 15, 341-366.

25. Marsh A, Gordon D, Heslop P et al. (2000) Housing deprivation and health: a longitudinal analysis. Housing Stud 15, 411-428.

26. Barlett PF (1980) Adaptive strategies in peasant agricultural production. Annu Rev Anthropol 9, 545-573.

27. Gonzalez G (2005) Population Ageing, Sustainable Development and Food Security in Rural Areas of Bolivia and Chile. Rome: FAO; available at http://www.fao.org/sd/ dim_pe1/pe1_050906_en.htm

28. Hadley C, Lindstrom D, Tessema F et al. (2009) Gender bias in the food insecurity experience of Ethiopian adolescents. Soc Sci Med 66, 427-438.

29. Food and Agriculture Organization of the United Nations (2003) Gender and Development Plan of Action: Agricultural Support System. Rome: FAO; available at http:// www.fao.org/docrep/005/y3969e/y3969e05.htm

30. Amah F, Odoi J, Obiri S et al. (2011) Food security and climate change in drought-sensitive savanna zones of Ghana. Mitigat Adaptat Strateg Glob Change 16, 291-306.

31. Bakewell-Stone P, Lieblein G \& Francis C (2008) Potentials for organic agriculture to sustain livelihoods in Tanzania. Int J Agric Sustain 6, 22-36.

32. Devendra C \& Chantalankhana C (2002) Animals, poor people, and food insecurity: opportunities for improved 
livelihoods through efficient natural resource management. Outlook Agric 31, 161-175.

33. World Bank (2007) World Development Report 2008: Agriculture for Development. Washington, DC: International Bank for Reconstruction and Development, World Bank; available at http://econ.worldbank.org/ WBSITE/EXTERNAL/EXTDEC/EXTRESEARCH/EXTWDRS/ EXTWDR2008/0,,contentMDK:21410054 menuPK:3149676 $\sim$ pagePK:64167689 piPK:64167673 theSitePK:2795143,00. html

34. Sebastian R, Lubowa A, Yeudal F et al. (2008) The association between household food security and urban farming in Kampala. In Healthy City Harvests: Generating Evidence to Guide Policy on Urban Agriculture, pp. 69-87 [DC Cole, D Lee-Smith and G Nasinyama, editors]. Lima: CIP/Urban Harvest and Makerere University Press.

35. Berti PR, Krasevec J \& FitzGerald S (2003) A review of the effectiveness of agriculture interventions in improving nutrition outcomes. Public Health Nutr 7, 599-609.

36. Orozco F, Cole DC, Muñoz V et al. (2007) Relationship among production systems, pre-school nutritional status and pesticide-related toxicity in seven Ecuadorian communities - a multi-case study approach. Food Nutr Bull 28, 2 Suppl., S247-S257. 